\title{
Identification of Implementation Program of Electricity Competency
}

\author{
Ija Darmana ${ }^{1, *}$, Nizwardi Jalinus ${ }^{2}$, Ganefri ${ }^{3}$ and Sukardi ${ }^{4}$ \\ ${ }^{1}$ Faculty of Industrial Technology, Universitas Bung Hatta Padang, West Sumatera, Indonesia. \\ ${ }^{1} \mathrm{PhD}$ Students (S3), Faculty of Engineering, Universitas Negeri Padang, West Sumatera, \\ Indonesia. \\ ${ }^{2,3,4}$ Faculty of Engineering, Universitas Negeri Padang, West Sumatera, Indonesia.
}

\begin{abstract}
This study aims to identify the implementation of technical personnel competency testing program. This study applies the Kirkpatrick model at four levels, namely: 1) the level of satisfaction of participants in the implementation of the program; 2) the level of understanding of the subject by the participants; 3 ) changes in the professional behavior of the participants in the proficiency tests after their return to work; 4) the impact of changes in the professional behavior of the participants in the skills tests. The identification of assessment instruments for each level is obtained from bibliographic studies relevant to the program. The results of the study concluded that the application of the Kirkpatrick model in this study was as follows: 1) short-term skills testing program; 2) Kirkpatrick model widely used to evaluate program training programs
\end{abstract}

\section{Introduction}

The ASEAN Economic Community calls for the abolition of rules that previously prevented the recruitment of foreign workers. Restrictions, particularly in the professional power engineering sector, are encouraged to be removed. MEA offers foreign workers opportunities to fill jobs and professions in Indonesia. A study by the World Labor Organization predicted that many companies would find their employees less qualified because of a lack of professional training.

Winterton skills $[1,2]$ are needed and expected in the workplace and refer to the knowledge, skills and attitudes needed for workers to work. Recognition of professional skills is obtained after conducting skills tests conducted by training institutions.

According to Sedarmayanti [3], competence is a fundamental characteristic of someone who has a direct influence or can predict good performance. Skill according to Sedarmayanti in his research "Testing competence rather than intelligence" is: skills and knowledge.

The phenomenon that occurs, participants in proficiency tests that run skill associations or institutions in West Sumatra, are relatively few, which will affect the mental attitude and professional ethics of the technical staff to deal with the competition on the free market. Participants in the skills tests held by APEI West Sumatra on December 1, 2016 in Padang,

\footnotetext{
${ }^{*}$ Corresponding author: ija.darmana@bunghatta.ac.id
} 
twenty-two people. On the basis of the phenomenon mentioned above, "the implementation of the proficiency test must be identified", ie whether a program of implementation of the skills tests requires an evaluation model to evaluate the program

\section{Literature Review}

Khandker [4], this evaluation approach can be carried out using quantitative methods (such as the collection of survey data or simulations) before or after the implementation of the program. This assessment predicts the impact of the program using the data before and after the implementation of the program. Although each evaluation model still has limitations, choosing the right model will have a direct impact on the quality of the information produced during the evaluation.

The researchers conducted a study of several research results in the form of journals and dissertations, including: Hoover [5] conducted a thesis study titled Evidence-based Interventions: Early Examination and Continuing Education.

Homklin [6] conducted a thesis entitled: Skills Certification System Training: The Case of the Automotive Industry in Thailand. Most research and training practices in Thailand focus on level one (response) and level two (learning) with the evaluation of the Kirkpatrick model. Preston [7] conducted a thesis study entitled: Perception of Leadership in Results and Evaluation of Return on Investment Training. This study applies a five-level evaluation of the return-on-investment model, level five. The purpose of this study was to assess how effectively the program has increased the value of organizations in the six largest Catholic health organizations in the United States. accurately reflect the expectations of organizational leaders.

Chang [8] conducted a thesis entitled: An Empirical Study of Kirkatrick's Evaluation Model in the Hospitality Industry. This study examines the Kirkpatrick training evaluation model [9] by evaluating sales training programs conducted in hotel organizations in Florida. The results of his research show that: the results of the analysis largely support this research hypothesis. There is a significant increase in the fact that booking agents completing the training deepen their knowledge of the content and skills required.

Farjad [10] in the journal Procedia-Social and Behavioral Sciences 46 (2012) 2837-2841, entitled: Effectiveness of the evaluation of university education by Kirkpatrick Model (case study: Islamshahr University). The results of the study indicate that training efficiency is below the standard level. The results of the effectiveness evaluation show that the reaction, learning, behavior and organizational level need to be improved.

Donald [11] from the perspective of health information management. Spring 2011, vol. 8 Number 2, p1-5. 5p, Using the Kirkatrick Evaluation Framework to Determine the Effectiveness of Health Information Management Programs and Programs. Researchers used the Kirkpatrick assessment framework to present models that can be used by health information instructors. According to the review literature, the identification of competency tests is necessary to prepare a competency test evaluation model.

\section{Methodology}

Moldovan [12], Procedia Technology 22, entitled Results Model Evaluation Training. Kirkpatrick evaluates the improvement of the model by linking the level of evaluation to the correct objectives. By following the PDCA cycle. The level of objectives includes results, performance, knowledge and motivation related to the level of evaluation of reactions, learning outcomes, and behavior. 


\section{Results and Discussions}

Level 1, at this level, a person must be able to perform tasks / routine work based on the understanding of work procedures / instructions under the supervision of the direct supervisor.

Level 2, at this level, a person must be able to perform routine tasks / work based on the application of procedures / instructions and the execution of tasks and work requiring: 1) the ability to solve problems.

Level 3, at this level, a person must be able to perform routine tasks / tasks based on procedures / instructions and perform tasks and tasks requiring the existence of: 1) Ability to analyze problems, 2) Ability to solve problems 4) Ability to coordinate and supervise subordinates. The pooling of similar skills is grouped into certain positions to carry out multilevel, fully trained and educated tasks. Clustering is called skill-based professional qualification.

Level 4, at this level, a person must be able to perform tasks / jobs that are able to use a number of procedures, in different, ordinary or unusual contexts, and with extended scope and demanding reasoning skills technical.

Identification results obtained:

1. Research instruments are needed. It is a tool used by researchers to collect research data by measuring them. This is a written directive in the form of a list of questions prepared to obtain information from respondents.

2. Questionnaire Instrument, the questionnaire is used in the needs analysis as a tool to determine the need to develop models for the assessment of the skills of the technical staff of the commercial electricity construction services. The respondents to this questionnaire are the users, namely the Institute or the Electricity Association and the Director.

3. Validation form, this instrument is used as a tool to determine the validation of the technical engineering competency test evaluation model of the electricity generation service activity that has already been designed to the need for a proficiency test.

4. The evaluation instructor seeks to know the validity of the evaluation model of the proficiency test of the technical staff of electrical engineering services by experts. Before conducting the research, the researchers compiled instruments based on indicators of implementation of skills tests at the BNSP and professional associations.

5. The scale used to compile the validation instrument in this study is the Liker scale. The validation form of the Electrical Engineering Technical Competency Test Evaluation Template contains evaluation elements that include elements of the electrical engineering services engineering competency assessment model and a questionnaire.

\section{Conclusion}

The identification of training participants 'assessments should be based on trainees' ability to achieve the objectives. Step 1, for feedback on training, how much training material was designed, and how well the trainer performed well. Step 2, learning includes written tests, oral exams and practical tests. In Step 3, the attitude / behavior includes the work of the employees at work to see if the employee correctly applies his knowledge and skills. In Step 4 , the impact includes the effect of the training on the organization on the impact of the training. Training is one of the most comprehensive methods to increase individual productivity and improve job performance in the work environment.

\section{References}


1. Jonathan Winterton, Typology of knowledge, skills and competences: clarification of the concept and prototype. Italy, (2006)

2. Jonathan Winterton, What Is Competence?, Human Resource Development International, Vol. 8, No. 1, 27-46, (2005)

3. Sedarmayanti, Human Resources and Work Productivity, Mandar Maju, Bandung, (2009)

4. Shahidur R. Khandker, Gayatri B. Koolwal and Hussain A. Samad, Handbook on Impact Evaluation, Quantitative Methods and Practices, Washington DC 20433, (2010)

5. N. Hoover, Evidence Based Intervention: An Examination of Pre-Service Training, Profesional Development, And Classroom Implementation. Texas A\&M UniversityCorpus Christi Corpus, (2013)

6. Tassanee HOMKLIN, Training Effectiveness of Skill Certification System: The Case of Automotive Industry in Thailand. Hiroshima University, (2014)

7. Kevin F. Preston, Leadership Perceptions Of Results And Return On Investment Training Evaluations. Colorado State University, (2010)

8. Ya-Hui Elegance Chang, An Empirical Study of Kirkpatrick's Evaluation Model in the Hospitality Industry. Florida International University, (2010)

9. Donald L. Kirkpatrick And James D. Kirkpatrick, Third Edition. Evaluating Programs The Four Levels. Westchester Book Group, (2006)

10. Shahrooz Farjad, Procedia-Social and Behavioral Sciences 46 (2012) 2837-2841. The Evaluation Effectiveness of training courses in University by Kirkpatrick Model (case study: Islamshahr university) (2012)

11. Rouse, Donald, Employing Kirkpatrick's Evaluation Framework to Determine the Effectiveness of Health Information Management Courses and Programs. Perspectives in Health Information Management. Spring2011, Vol. 8 Issue 2, p1-5. 5p, (2011)

12. Liviu Moldovan, Training Outcome Evaluation Model. Procedia Technology 221184 1190, (2016) 